International Journal of Computational Engineering Science

Vol. 2, No. 4 (2001) 675-677

(C) Imperial College Press

\title{
AUTHOR INDEX \\ VOLUME 2 (2001)
}

Abdennour, R. B., see M'Sahli, F.

2 (2001) $287-307$

Abdennour, R. B., see M'Sahli, F.

4 (2001) 633-651

Ahmadi, A. R., see Surana, K. S.

4 (2001) 653-673

Ascione, L. and Feo, L., On the Mechanical Behaviour of Thin-Walled

Beams of Open Cross-Section: An Elastic Non-Linear Theory

Ascione, L. and Feo, L., On the Non-Linear Statical Behaviour of

3 (2001) 479-511

Thin-Walled Elastic Beams of Open Cross-Section: A Numerical

Approach

Averill, R. C., see Yip, Y. C.

Barkdoll, B., see Khan, A. A.

Baskar, S., Subbaraj, P., and Rao, M. V. C., Performance of Hybrid

Real Coded Genetic Algorithms

Beskok, A. and Warburton, T. C., Arbitrary Lagrangian Eulerian

Analysis of a Bidirectional Micro-Pump Using Spectral Elements

Beskos, D., see Hatzigeorgiou, G.

Boatwright, J. T. and Palazotto, A. N., Fatigue Loading

Considerations for a Composite Cylindrical Shell with a

Square Cutout

Castro, F. J. B. and Militello, C., A Modal Error Indicator

Based on a Work-Cancellation Property of Energy-Orthogonal

Finite Elements

Chen, A. Y.-J., see Guan, H.

Chen, S.-H., see Liang, S.-J.

Chenot, J.-L., see Teodorescu, M.

Chung, I., Hwang, C.-S., and Shon, J., Adaptive Concurrency

Control Schemes Supporting Mobile Client Caching

Czekanski, A., see Meguid, S. A.

Dou, H.-S. and Phan-Thien, N., Numerical Difficulties at High

Elasticity for Viscoelastic Flow Past a Confined Cylinder

Ducloux, R., see Teodorescu, M.

Fayeche, C., see M'Sahli, F.

Feo, L., see Ascione, L.

Feo, L., see Ascione, L.

Gendy, A. S. and Saleeb, A. F., Mixed Finite Element Modeling for the Dynamics of Beam Assemblages Undergoing Large Overall Motions in Space

Guan, H., Chen, A. Y.-J., and Loo, Y.-C., Topology Optimization of Bridge Type Structures with Stress and Displacement Constraints

3 (2001) 513-536

1 (2001) 137-180

3 (2001) 453-467

4 (2001) 583-601

1 (2001) 43-57

2 (2001) 267-286

2 (2001) 223-248

4 (2001) 569-582

2 (2001) 199-221

4 (2001) 557-567

3 (2001) 425-452

3 (2001) 537-555

1 (2001) 75-93

2 (2001) 249-266

3 (2001) 425-452

2 (2001) 287-307

3 (2001) 479-511

3 (2001) 513-536

2 (2001) 309-338

2 (2001) 199-221 
Hatzigeorgiou, G., Beskos, D., Theodorakopoulos, D., and Sfakianakis, M., A Simple Concrete Damage Model for Dynamic FEM

Applications

2 (2001) 267-286

Hwang, C.-S., see Chung, I.

Jayalakshmi, G. A., Sathiamoorthy, S., and Rajaram, R., A Hybrid Genetic Algorithm - A New Approach to Solve Traveling Salesman Problem

3 (2001) 537-555

Karim, Md. S., see Rathod, H. T.

Khan, A. A. and Barkdoll, B., Two-Dimensional Depth-Averaged Models for Flow Simulation in River Bends

Ksouri, M., see M'Sahli, F.

Ksouri, M., see M'Sahli, F.

Lee, J.-H., see Liang, S.-J.

Li, W., Steven, G. P., and Xie, Y. M., Shape Design for Two- and Three-Dimensional Contact Problems Using an Evolutionary Method

Liang, S.-J., Lee, J.-H., Chen, S.-H., and Shiau, J.-H., Networked Collaborative Environment for Hydro-Engineering

Liew, K. M., see Ren, J.

Liu, Z. Y., see Ng, E. Y. K.

Loo, Y.-C., see Guan, H.

Meguid, S. A., see Ren, J.

Meguid, S. A., Xue, H., and Czekanski, A., Numerical and

Experimental Studies of Multiple Discs in Contact

Militello, C., see Castro, F. J. B.

Mocellin, K., see Teodorescu, M.

M'Sahli, F., Abdennour, R. B., and Ksouri, M., Identification and Predictive Control of a Nonlinear Process Using a Parametric Volterra Model

M'Sahli, F., Fayeche, C., Abdennour, R. B., and Ksouri, M., Application of Adaptive Controllers for the Temperature Control of a Semi-Batch Reactor

Ng, E. Y. K. and Siauw, W. L., Direct Solution of Navier-Stokes Equation on Moving Physical Computational Domain

Ng, E. Y. K., Liu, Z. Y., and Soong, C. Y., Numerical Evaluation of Heat and Fluid Flow within Rotating Disks

Palazotto, A. N., see Boatwright, J. T.

Pavan Kumar, D. V. T. G., see Prathap, G.

Petti, S. R., see Surana, K. S.

Phan-Thien, N., see Dou, H.-S.

Prathap, G. and Pavan Kumar, D. V. T. G., Error Analysis of

Timoshenko Beam Finite Element Dynamic Models

Rajaram, R., see Jayalakshmi, G. A.

Rao, G. V., see Wilfred, J.

Rao, M. V. C., see Baskar, S.

Rathod, H. T. and Karim, Md. S., An Explicit Integration Scheme Based on Recursion and Matrix Multiplication for the Linear Convex Quadrilateral Elements

Reddy, J. N., see Surana, K. S.

2 (2001) 339-355

1 (2001) 95-135

3 (2001) 453-467

2 (2001) 287-307

4 (2001) 633-651

4 (2001) 557-567

2 (2001) 181-198

4 (2001) 557-567

4 (2001) 621-632

1 (2001) 11-30

2 (2001) 199-221

4 (2001) 621-632

1 (2001) 75-93

4 (2001) 569-582

3 (2001) 425-452

4 (2001) 633-651

2 (2001) 287-307

3 (2001) 469-477

1 (2001) 11-30

2 (2001) 223-248

1 (2001) $1-10$

4 (2001) 653-673

2 (2001) 249-266

1 (2001) 1-10

2 (2001) 339-355

4 (2001) 603-620

4 (2001) 583-601

1 (2001) 95-135

4 (2001) 653-673 
Ren, J., Liew, K. M., and Meguid, S. A., Nonlinear FE Analysis of the Hysteresis Behavior of SMA

Saleeb, A. F., see Gendy, A. S.

Sathiamoorthy, S., see Jayalakshmi, G. A.

4 (2001) 621-632

2 (2001) 309-338

2 (2001) 339-355

Sfakianakis, M., see Hatzigeorgiou, G.

Shiau, J.-H., see Liang, S.-J.

Shon, J., see Chung, I.

Siauw, W. L., see Ng, E. Y. K.

Singh, G., see Wilfred, J.

Soong, C. Y., see Ng, E. Y. K.

Steven, G. P., see Li, W.

Subbaraj, P., see Baskar, S.

Surana, K. S. and Van Dyne, D. G., Nonweak/Strong Solutions in Gas Dynamics: A $C^{11}$ p-Version STLSFEF in Eulerian Frame of Reference Using $\rho, U, T$ Primitive Variables

Surana, K. S. and Van Dyne, D. G., Nonweak/Strong Solutions in Gas Dynamics: A $C^{11}$ p-Version STLSFEF in Lagrangian Frame of Reference Using $\rho, U, T$ Primitive Variables

Surana, K. S., Petti, S. R., Ahmadi, A. R., and Reddy, J. N., On $p$-Version Hierarchical Interpolation Functions for Higher-Order Continuity Finite Element Models

Teodorescu, M., Mocellin, K., Chenot, J.-L., and Ducloux, R., A Partly-Explicit Finite Element Formulation for the Forging Process

Theodorakopoulos, D., see Hatzigeorgiou, G.

Thonchangya, N., Analysis of the Bending of a Uniformly Loaded Rectangular Plate with Variable Width Corner Supports

Torii, S., Unsteady Thermal Fluid Transport Phenomena in Square Cavity under Reduced Gravity

Van Dyne, D. G., see Surana, K. S.

Van Dyne, D. G., see Surana, K. S.

Warburton, T. C., see Beskok, A.

Wilfred, J., Singh, G., and Rao, G. V., A 2-Node Beam Element Based on Coupled Displacement Field for Buckling Analysis of Curved Composite Beams

Xie, Y. M., see Li, W.

Xue, H., see Meguid, S. A.

Yip, Y. C. and Averill, R. C., A Three-Dimensional Laminated Plate Finite Element with High-Order Zig-Zag Sublaminate Approximations

2 (2001) 267-286

4 (2001) 557-567

3 (2001) 537-555

3 (2001) 469-477

4 (2001) 603-620

1 (2001) 11-30

2 (2001) 181-198

4 (2001) 583-601

3 (2001) 383-423

3 (2001) 357-382

4 (2001) 653-673

3 (2001) 425-452

2 (2001) 267-286

1 (2001) 31-42

1 (2001) 59-73

3 (2001) 357-382

3 (2001) 383-423

1 (2001) 43-57

4 (2001) 603-620

2 (2001) 181-198

1 (2001) 75-93

1 (2001) 137-180 